\section{Pattern and outcome of admissions at the Emergency Pediatric Unit of Federal Medical Centre Nguru, Yobe State, Nigeria}

\author{
Umar Isa Umar, ${ }^{1}$ Isyaku Lawal \\ Muhammed, ${ }^{2}$ Garba Dayyabu Gwarzo ${ }^{3}$ \\ ${ }^{1}$ Endocrinology Unit, Department of \\ Pediatrics, Bayero University Kano, \\ Kano State; ${ }^{2}$ Department of Pediatrics, \\ Federal Medical Centre Nguru, Yobe \\ State; ${ }^{3}$ Gastroenterology Unit, \\ Department of Pediatrics, Bayero \\ University Kano, Nigeria
}

\begin{abstract}
Emergency care involves the care of patients with acute illnesses or injuries that require immediate medical attention. Periodic evaluation of emergency unit generally provides an excellent means of auditing hospital performance and assessing the quality of services in the hospital. The aim was to determine the pattern and outcome of Pediatrics admissions at the emergency Pediatrics unit of Federal Medical Centre Nguru, Yobe State, Nigeria. This is a retrospective review of case notes of all children admitted into emergency unit at the Pediatrics Department of Federal Medical Centre Nguru between November 2015 and October 2017. The data was entered into SPSS version 20 soft-ware and a descriptive analysis was used for analysis of the data. A total of 3289 patients aged from 1 month to 192 months (16 years) were seen. The mean age was $52.1 \pm 46.3$ months. There were $57.8 \%$ males and $42.2 \%$ females. Underfive children admitted were $62.2 \%$, children 5 years and above were $37.8 \%$. The common indications for admission were malaria (24.8\%), diarrhea (11.1\%), sickle disease $(9.8 \%)$ and sepsis $(7.4 \%)$. Most $(50.0 \%)$ of the patients were transferred to the ward, while $35.0 \%$ discharged home from the EPU. Mortality was $11.6 \%$, while $0.8 \%$ of the patients were discharged against medical advice and 1.2\% absconded from admission. Infections especially malaria, pneumonia and diarrhea diseases are the most prevalent causes of childhood morbidity and mortality in emergency pediatric unit of the hospital, and children less than 5 years of age are commonly affected.
\end{abstract}

\section{Introduction}

Children are often brought to hospitals in critical state. ${ }^{1}$ Therefore, it is necessary to have an effective and efficient children emergency unit in every hospital. Emergency care involves the care of children with acute illnesses or injuries that require immediate medical attention. ${ }^{1}$ Good emergency services, especially for children, is one of the fundamental aims of the World Health Assembly. This aim is to improve the quality of life of individuals and their survival through Millennium development goals. ${ }^{2}$ Periodic evaluation of emergency unit generally gives an insight into the existing services of health care system, whether effective or otherwise. In addition, it is also an excellent means of auditing hospital performance and assessing the quality of services in the hospital.

In Nigeria some studies were conducted to assess the pattern and outcome of admissions in children emergency units and all the studies have shown a predominance of infectious diseases as the major causes of morbidities and mortality in children. ${ }^{3-8}$ However, at this center there has been no reported hospital audit of pediatric admissions, therefore it is in this respect that we undertook the first hospital audit of pediatric medical admissions to evaluate the morbidity and mortality pattern. This study, therefore, aims to examine the pattern and outcome of admissions at the emergency pediatrics unit (EPU) of Federal Medical Centre (FMC) Nguru, Yobe State northeastern Nigeria over a two-year period.

\section{Materials and Methods}

The study involved a retrospective review of case notes of all children admitted into EPU in the Pediatrics Department of FMC Nguru between November 2015 and October 2017. Case files of the patients were manually retrieved, and a structured questionnaire was used to extract relevant information which included age, gender, definitive diagnosis (those with complete investigations) or probable diagnosis (those without complete investigations or died early), duration of hospital stay and outcome. Outcome was categorized as transferred to the ward, discharged home, death, referred out, discharged against medical advice (DAMA) and absconded from admission.

Approval for the study was obtained from the Ethics Committee of Federal Medical Centre Nguru, before commencement of the study.
Correspondence: Umar Isa Umar, Department of Pediatrics, Bayero University Kano, P.M.B. 3011, Kano, 700001 Nigeria.

E-mail: umarpaed@gmail.com

Key words: Pattern; Admission; Outcome; Pediatric emergency; Nguru; Nigeria.

Contributions: the authors contributed equally.

Conflict of interest: the authors declare no potential conflict of interest.

Funding: none.

Received for publication: 17 July 2018.

Revision received: 25 September 2018.

Accepted for publication: 25 September 2018.

This work is licensed under a Creative Commons Attribution NonCommercial 4.0 License (CC BY-NC 4.0).

CCopyright U.I. Umar et al., 2018

Licensee PAGEPress, Italy

Pyramid Journal of Medicine 2018; 1:1 doi:10.4081/pjm.2018.1

\section{Analysis}

The data was entered into SPSS version 20 software and a descriptive analysis was used for analysis of the data.

\section{Results}

A total of 3289 patients aged from 1 month to 192 months (16 years) were seen with a mean age of $52.1 \pm 46.3$ months during the period. There were 1902 (57.8\%) males and 1387 (42.2\%) females, with male to female ratio of 1.4:1 (Table 1). The total number of under-five children admitted during the study period was $2046(62.2 \%)$ while the remaining $1243(37.8 \%)$ were children 5 years and above. In both groups, there was preponderance of males as shown in Figure 1. A representation of monthly admissions in Figure 2 shows that the number of admissions increased steadily from June and peaked in October. This corresponds to the beginning and end of rainy season respectively.

The common indications for admission were severe malaria $(24.8 \%)$, acute diarrhea $(11.1 \%)$, sickle cell disease $(9.8 \%)$ and Sepsis $(7.4 \%)$. Least common morbidities were HIV $(0.5 \%)$, bronchiolitis $(0.3 \%)$ and renal failure $(0.1 \%)$ as shown in Table 2.

The outcome for all admissions within the period studied is illustrated in Figure 3. Half $(50 \%)$ of all the patients were transferred to the ward for further management, after initial resuscitation and stabilization. Significant percentage of the patients $(35 \%)$ 
recovered completely in the emergency room and was discharged home. Mortality was $11.6 \%$, while $0.8 \%$ of the patients were discharged against medical advice and 1.2\% absconded from admission. Mortality tended to follow the pattern of admission with highest mortalities occurring between August and October (Figure 2). Overall, $382(11.6 \%)$ patients (219 males, 163 females) died in the emergency room as shown in Table 3. Under-five deaths formed $70.7 \%(270 / 382)$ of all the mortalities (Table 4). Based on age groups, the highest death $(34.6 \%)$ occurred in $12-35$ months age group while the least $(8.1 \%)$ was in those over 120 months as shown in Figure 4. The overall leading cause of death in the unit was severe malaria which accounted for 81 of $382(21.2 \%)$ deaths. This was followed by acute diarrhea $(15.2 \%, 58 / 382)$, sepsis $(10.7 \%, 41 / 382)$, PEM $(9.2 \%$, $35 / 382)$, complicated measles $(5.8 \%$, $22 / 382)$, sickle cell anemia $(4.5 \%, 17 / 382)$, and surgical conditions $(3.9 \%, 15 / 382)$. Major causes of death in children below 5 years were diarrheal disease $19.3 \%$ (52/270), complicated malaria (18.3\%) and protein-energy malnutrition (PEM) (13\%) as shown in Table 5. While in children above 5 years the major causes of death were complicated malaria (27.7\%) and sickle cell anemia with various crises $(11.6 \%)$, and surgical conditions ( $8 \%$ ) as shown in Table 6 .

Table 1. Age and sex distribution of study subjects.

\begin{tabular}{lccc} 
Age (months) & Male (\%) & Female (\%) & Total (\%) \\
$<12$ & $372(11.3)$ & $233(7.1)$ & $605(18.4)$ \\
$12-35$ & $552(16.8)$ & $403(12.3)$ & $955(29.1)$ \\
\hline $36-59$ & $289(8.8)$ & $197(6.0)$ & $486(14.8)$ \\
$60-120$ & $486(14.8)$ & $395(12.0)$ & $881(26.8)$ \\
$>120$ & $203(6.2)$ & $159(4.8)$ & $362(11.0)$ \\
Total & $1902(57.8)$ & $1387(42.2)$ & $3289(100)$
\end{tabular}

\section{Discussion}

The common causes of morbidity amongst admitted children in this center were severe malaria, diarrhea, pneumonia, sepsis and protein energy malnutrition. Ibeziako and Ibekwe $^{3}$ reported severe malaria with anemic heart failure followed by acute respiratory tract infections and diarrheal diseases as the most common causes of admissions in Enugu South East

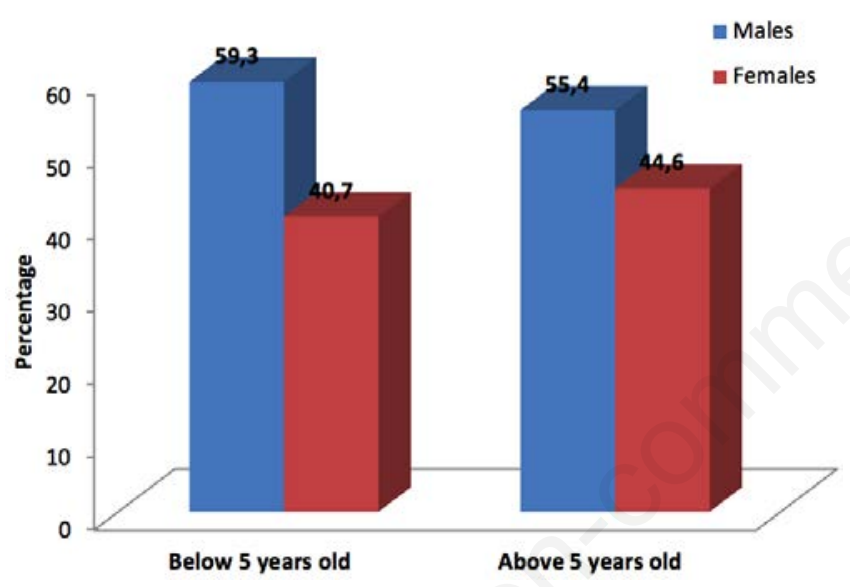

Figure 1. Pattern of admission below and above 5 years.

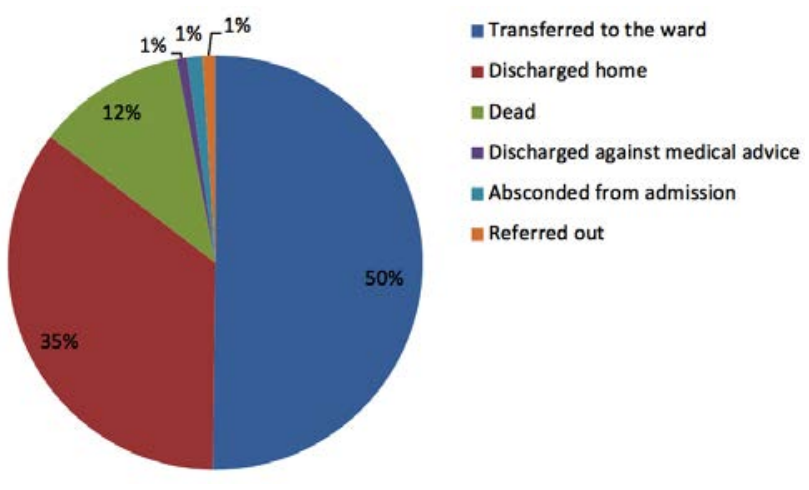

Figure 3. Outcome of admission.

Figure 2. Pattern of morbidity and mortality by month.
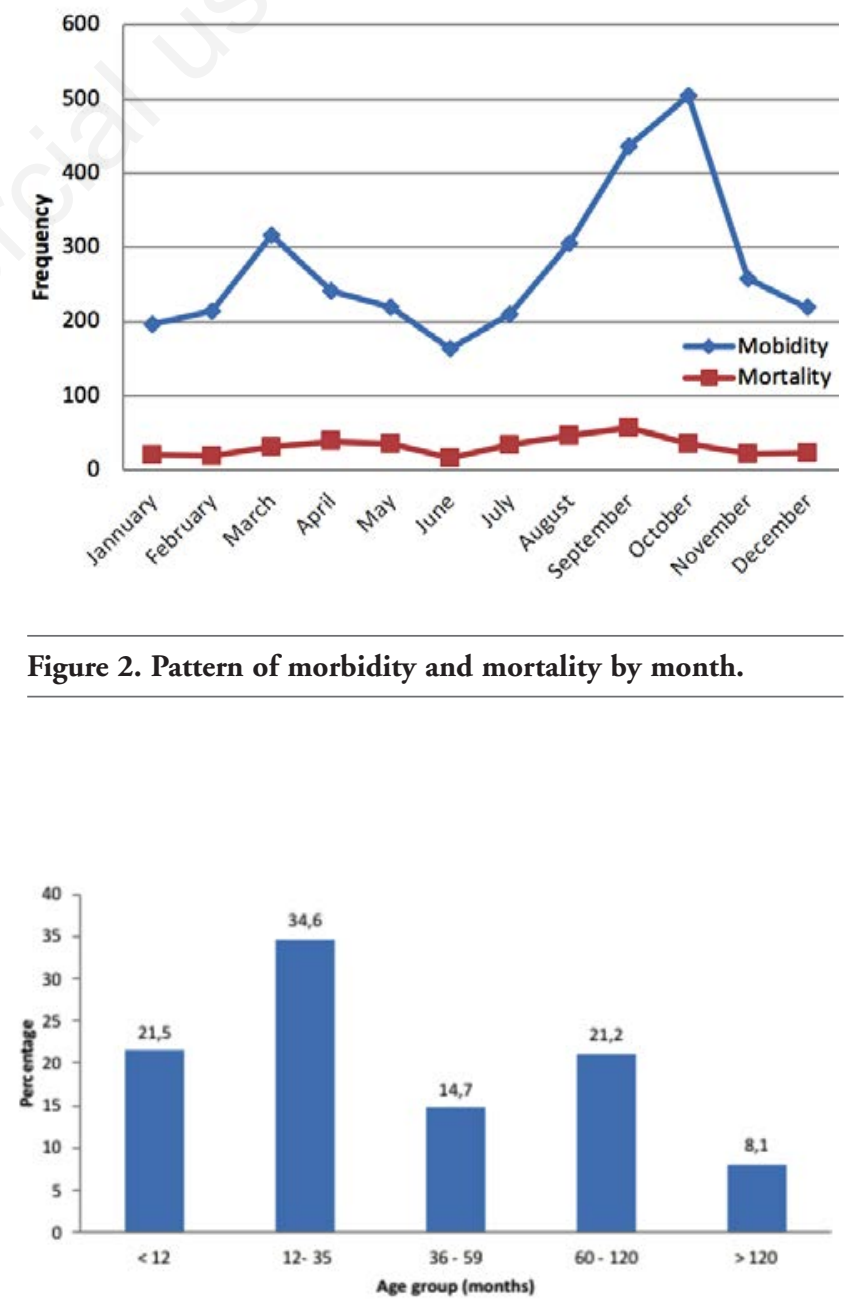

Figure 4. Pattern of mortality by age group. 
Nigeria, which was similar to other reports by Iloh et al. ${ }^{4}$ and Okechukwu ${ }^{5}$ in Owerri and Abuja capital territory of Nigeria respectively. A similar pattern has also been shown from the emergency departments of Jos, ${ }^{6}$ Lagos, ${ }^{7}$ and Ilorin. ${ }^{8}$ This finding is also similar to what was observed in other parts of Nigeria and other resource poor settings. ${ }^{9-11}$ These findings have shown that morbidity pattern in Nigerian children has persistently remained the same over decades. This may be due to poor socioeconomic conditions, and lack of or incomplete immunization. Furthermore, infections such as diarrheal diseases, pneumonia and complicated malaria were recognized by WHO, ${ }^{12}$ as the leading cause of childhood morbidities and mortalities, especially in the under-5 age group in resource poor settings. In addition, we observed some cases of childhood immunizable diseases in children below and above the age of five years: measles, pertussis, tuberculosis and tetanus. This may possibly be due to poor immunization coverage against these diseases. But over the study period there was only one suspected case of polio, likely due to ongoing intensive immunization campaign against polio in Nigeria. This may as well buttress the fact that there is poor immunization against other immunizable diseases.

Majority of the children hospitalized were under the age of 5 years. This is similar to what was found in Gusau, ${ }^{9}$ Port Harcourt, ${ }^{13}$ Benin, ${ }^{14}$ and Ilesa. ${ }^{15}$ This is in keeping with the fact that Nigerian has mainly young population $(42.54 \%$ of her population between the ages of 0-14 years, out of which children between 0 and 4 years constitutes the highest percentage of $16.09 \%) .{ }^{16,17}$ In addition, it could also be due to the vulnerability of this age group (under-five years) as a result of incomplete immunity against common infections.

There is male preponderance in EPU admission pattern in this study, and several studies also have reported higher admis-

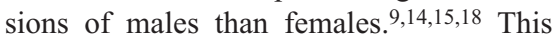
male preponderance found in our study could be due to the fact that male children are more vulnerable to infections or that the society pays more attention to male children than females. On the other hand, Alams et al. ${ }^{19}$ attributes it to possibly cultural factors like preference in seeking medical care for boys.

The peak period of admission was between June and October. This period corresponds to the period of the rainy season in this part of Nigeria. The rainy season comes with many health problems, especially infections such as malaria. In this study malaria is the most common cause of admission. Malaria has always been the biggest public health problem and the commonest disease in many parts of Africa, including Nigeria. ${ }^{20}$ According to research,

Table 2. Pediatric morbidities seen at the emergency pediatrics unit.

\begin{tabular}{lcc} 
Diagnosis & Frequency $(\mathbf{N})$ & Percentage \\
Severe Malaria & 814 & 24.8 \\
Diarrheal disease & 365 & 11.1 \\
\hline Sickle cell anemia & 321 & 9.8 \\
Sepsis & 280 & 8.5 \\
\hline Bronchopneumonia & 229 & 7.0 \\
Protein energy malnutrition & 192 & 5.8 \\
\hline Surgical conditions* & 145 & 4.4 \\
Febrile seizure & 121 & 3.7 \\
\hline Measles & 109 & 3.3 \\
Severe anemia & 98 & 3.0 \\
\hline Bacterial meningitis & 81 & 2.5 \\
Heart failure & 75 & 2.3 \\
\hline Enteric fever & 55 & 1.7 \\
Poisoning & 50 & 1.5 \\
\hline Nephrotic syndrome & 33 & 1.0 \\
Pertussis & 32 & 0.9 \\
\hline Malignancies & 26 & 0.8 \\
Tuberculosis & 26 & 0.8 \\
\hline Seizure disorder & 22 & 0.7 \\
Urinary stones & 22 & 0.7 \\
\hline Acute glomerulonephritis & 21 & 0.6 \\
Tetanus & 19 & 0.6 \\
\hline Acute asthma & 17 & 0.5 \\
HIV & 16 & 0.5 \\
\hline Bronchiolitis & 11 & 0.3 \\
Renal failure & 8289 & 2.6 \\
\hline Miscellaneous** & & 100 \\
Total & 26 & \\
\hline & & 0.1 \\
\hline
\end{tabular}

*Enteric fever with perforation, head injury, appendicitis, trauma, upper gastrointestinal bleeding, intussusception, foreign body aspiration, strangulated hernia, acute abdomen, ruptured viscus, hydrocele, abscess, epigastric hernia, umbilical hernia. ${ }^{*}$ Septic arthritis, recurrent abdominal pain, acute flaccid paralysis, infantile colic, rheumatic fever, rectal prolapse, urticaria, orbital abscess, muscular dystrophy, skin infection, chicken pox, bleeding diasthesis, viral hepatitis, burns, gastritis, cellulitis, diabetic ketoacidosis

Table 3. Pattern of outcome of admission among various age groups.

\begin{tabular}{lccccccc} 
Outcome & \multicolumn{7}{c}{ Age Group (months) } \\
& $<12$ & $12-35$ & $36-59$ & $60-120$ & $>120$ & Total (\%) \\
Transferred to the ward & 295 & 515 & 245 & 441 & 158 & $1654(50)$ \\
Discharged home & 209 & 285 & 171 & 329 & 161 & $1155(35)$ \\
\hline Dead & 82 & 132 & 56 & 81 & 31 & $382(11.6)$ \\
Discharged against medical advice & 6 & 4 & 2 & 10 & 4 & $26(0.8)$ \\
\hline Absconded from admission & 8 & 13 & 7 & 9 & 3 & $40(1.2)$ \\
Referred out & 5 & 7 & 4 & 11 & 5 & $32(1.0)$ \\
\hline
\end{tabular}

Table 4. Age and sex distribution of the mortalities.

\begin{tabular}{lccc} 
Age & Male $(\%)$ & Female $(\%)$ & Total $(\%)$ \\
$<5$ years & $150(39.3)$ & $120(31.4)$ & $270(70.7)$ \\
$>5$ years & $69(18.1)$ & $43(11.3)$ & $112(29.3)$ \\
\hline Total & $219(57.3)$ & $163(42.7)$ & $382(100)$ \\
\hline
\end{tabular}


malaria transmission in Nigeria high throughout the year but especially during and immediately after the rainy seasons. Earlier studies done here in Nigeria recorded a similar peak period of admission, particularly between July and November. ${ }^{21.22}$ Similarly, the study done in Nairobi, Kenya by Ye et $a l .{ }^{23}$ reported a peak period of admission between April and June which corresponds to the rainy season in Nairobi. This then implies that people need to be more prepared and pro-active towards infection control and malaria prevention by preventing mosquito bite through use of insecticide-treated mosquito nets, indoor residual spraying and prevent water from stagnating in the environment.

The outcome of admission showed that $35 \%$ of the children were discharge home and $50 \%$ transferred to the ward after initial resuscitation and stabilization for further management. This finding is similar to what was observed by Ndukwu in Nnewe. ${ }^{24}$ The outcome with respect to discharge against medical advice (DAMA), referred out to other facilities and absconding from admission was $1 \%$ each. Our DAMA was, however, higher than $0.1 \%$ reported previously amongst emergency room admissions in Enugu, ${ }^{3}$ but lower than $1.5 \%$ reported amongst pediatric patients in Abakaliki. ${ }^{25}$ It was, however, similar to that reported in Asaba $^{26}$ and Abuja. ${ }^{5}$ The $11.6 \%$ mortality recorded here is remarkably higher than that by other Nigerian authors..$^{3,5-8}$ Reasons for these differences in outcome could be due to methodology as some studies were conducted in both neonatal and post-neonatal children, some included surgical patients; and also, the duration of study periods vary. Another reason could be the type of hospital and presence of other referral hospitals in the state.

Most of the mortality occurred in children under the age of five, which is similar to what was observed in some studies. ${ }^{3,8,9,13}$ Majority of the mortality in this age group was due to complicated malaria, diarrhea, sepsis and pneumonia. Similar observation was made by Abhulimhen-Iyoha and Okolo $^{14}$ in Benin Fajolu and Egri-Okwaji, ${ }^{27}$ in Lagos and other studies. $8,28,29$ In children above the age of five years the mortality was mainly due to malaria, sickle cell anemia with various crises and surgical conditions. More males died than females which could be due to the fact that there were more males admitted during the study period. This was also observed in Port Harcourt, ${ }^{13}$ Ilorin, ${ }^{8}$ Ibadan, ${ }^{29}$ and India. ${ }^{28}$ Therefore, infections (especially malaria, pneumonia), diarrhea and malnutrition are still the leading causes of childhood mortality. This is probably due to poor practice of the multi-

Table 5. Causes of mortality in children below the age of 5 years.

\begin{tabular}{lcc} 
Diagnosis & Frequency (N) & Percentage \\
Diarrhea & 52 & 19.3 \\
Severe Malaria & 50 & 18.5 \\
\hline Protein energy malnutrition & 35 & 13.0 \\
Sepsis & 32 & 11.9 \\
\hline Bronchopneumonia & 21 & 7.8 \\
Measles & 18 & 6.7 \\
\hline Bacterial meningitis & 8 & 3.0 \\
Severe anemia & 8 & 3.0 \\
\hline Heart failure & 6 & 2.2 \\
Surgical conditions* & 6 & 2.2 \\
\hline Miscellaneous** & 5 & 1.8 \\
Sickle cell anemia & 4 & 1.5 \\
\hline Poisoning & 4 & 1.5 \\
Febrile seizures & 4 & 1.5 \\
Tetanus & 3 & 1.1 \\
Pertussis & 3 & 1.1 \\
\hline Tuberculosis & 3 & 1.1 \\
Malignancies & 3 & 1.1 \\
\hline HIV & 2 & 0.7 \\
Enteric fever & 2 & 0.7 \\
\hline Asthma & 1 & 0.4 \\
Nephrotic & 1 & 0.4 \\
\hline Renal failure & 1 & 0.4 \\
Total & 270 & 100 \\
\hline
\end{tabular}

*Enteric fever with perforation, head injury, appendicitis, trauma, upper gastrointestinal bleeding, intussusception, foreign body aspiration, strangulated hernia, acute abdomen, ruptured viscus, hydrocele, abscess, epigastric hernia, umbilical hernia. ${ }^{*}$ Septic arthritis, recurrent abdominal pain, acute flaccid paralysis, infantile colic, rheumatic fever, rectal prolapse, urticaria, orbital abscess, muscular dystrophy, skin infection, chicken pox, bleeding diasthesis, viral hepatitis, burns, gastritis, cellulitis, diabetic ketoacidosis.

Table 6. Causes of mortality in children above the age of 5 years.

\begin{tabular}{lcc} 
Diagnosis & Frequency $(\mathbf{N})$ & Percentage \\
Severe Malaria & 31 & 27.7 \\
Sickle cell anemia & 13 & 11.6 \\
\hline Surgical conditions & 9 & 8.0 \\
Sepsis & 9 & 8.0 \\
\hline Heart failure & 6 & 5.4 \\
Enteric fever & 6 & 5.4 \\
\hline Miscellaneous & 5 & 4.5 \\
Diarrhea & 5 & 4.5 \\
\hline Measles & 4 & 3.8 \\
Severe anemia & 4 & 3.8 \\
\hline Sepsis & 3 & 2.7 \\
Tetanus & 3 & 2.7 \\
\hline Bacterial meningitis & 3 & 2.7 \\
Tuberculosis & 3 & 2.7 \\
\hline Malignancies & 3 & 2.7 \\
Renal failure & 3 & 2.7 \\
\hline Nephrotic syndrome & 2 & 1.8 \\
Acute glomerulonephritis & 2 & 1.8 \\
\hline HIV & 1 & 0.9 \\
Total & 112 & 100
\end{tabular}


ple control measures for these diseases; hygiene, sanitation, availability of clean water and strengthening of immunization.

\section{Conclusions}

Infections especially malaria, pneumonia and diarrhea diseases are the most prevalent causes of childhood morbidity and mortality in emergency pediatric unit of the hospital, and children less than 5 years of age are commonly affected. There is need for effective control measures for the prevention of these diseases and to reduce the impact on the health of children in our locality and in Nigeria generally.

\section{References}

1. Guidelines for Pediatric Emergency Care Facilities. Committee on Pediatric Emergency Medicine. Pediatrics 1995;96:526-37.

2. Iloh GU, Amadi AN, Nwankwo BO, Ugwu VC. Common under-five morbidity in south-eastern Nigeria: A study of its pattern in a rural mission General Hospital in Imo state. Niger J Med 2011 ;22:99-104.

3. Ibeziako SN, Ibekwe RC. Pattern and outcome of admissions in the children's emergency room of the University of Nigeria Teaching Hospital, Enugu. Niger J Paediatr 2002;29:103-7.

4. Iloh GU, Ofoedu JN, Njoku PU, et al. The Magnitude of Under-five Emergencies in a Resource-poor Environment of a Rural Hospital in Eastern Nigeria: Implication for Strengthening the House-hold and Community-integrated Management of Childhood Illnesses. North Am J Med Sci 2012;4:344-9.

5. Okechukwu AA, Nwalozie C. Morbidity and mortality pattern of admissions into the emergency pediatric unit of University of Abuja Teaching Hospital, Gwagwalada. Niger J Med 2011;20:109-13.

6. Ighogboja IS, Angyo I, Okolo AA, Szlachetka R. Morbidity and mortality patterns of pediatric emergencies in Jos. Niger Med Pract 1995;30:15-8.

7. Ezeaka VC, Grange AO, Ogunbase AO. Childhood morbidity and mortality at the Lagos University Teaching Hospital
(LUTH) Lagos. Niger J Paediatr 2002; 29:91-5.

8. Adeboye MA, Ojuawo A, Adeniyi A, et al. Pattern of deaths occurring within the first 24 hours of admission between February and July 2001 in the emergency pediatric unit, University of Ilorin Teaching Hospital. Niger J Paediatr 2001;29:92-5.

9. Bilkisu GI, Aminu MS, Sunday OO, et al. Pattern of medical childhood morbidity and mortality in a new specialist hospital in Gusau, Nigeria. Ann Nigerian Med 2014;8:15-9

10. Sa'ad YM, Hayatu A, Al-Mustapha II, et al. Morbidity and mortality of childhood illnesses at the emergency pediatric unit of a tertiary hospital, northeastern Nigeria. Sahel Med J 2015;18:1-3

11. UNICEF Division of Policy and Strategy. Committing to Child Survival: A Promise Renewed. Progress Report; 2013. Available from: http://www.apromiserenewed.org.

12. WHO. World Health Report 2000, Health System: Improving performance. Geneva: World Health Organization; 2000.

13. George IO, Tabansi PN. An audit of cases in the children emergency ward in a Nigerian Tertiary Tospital. Pak J Med Sci 2010;26:740-3.

14. Abhulimhen-Iyoha BI, Okolo AA. Morbidity and mortality of childhood illnesses at the emergency pediatric unit of the University of Benin Teaching Hospital, Benin city. Niger J Paediatr 2012;39:1-74.

15. Sule SS. Childhood morbidity and treatment pattern at the multipurpose health center, Ilesa, Nigeria. Niger J Med 2003;12:145-9.

16. CIA. The World Factbook - Central Intelligence Agency. Available from: www.cia.gov. Accessed: 2018-04-10.

17. Lysonski S. Nigeria in transition: acculturation to global consumer culture. J Consum Market 2013;30:493-508.

18. Ugwu GI. Pattern and outcome of pediatric admission in a tertiary hospital in the Niger delta region of Nigeria: A two year prospective study. Int J Med Appl Sci 2012;1:15-29.

19. Alam N, van Ginneken JK, Timaeus I. Determinants of perceived morbidity and use of health services by children less than 15 years old in rural
Bangladesh. Matern Child Health J 2009;13:119-29.

20. National Center for Infectious Diseases, Division of Parasitic Diseases. Geographic Distribution and Epidemiology of Malaria. Information on Malaria, Apr 2004. Provided by the U.S. Centers for Disease Control and Prevention. [Last accessed on 2018 Jan 01].

21. Duru C, Peterside O, Akinbami F. Pattern and outcome of admissions as seen in the pediatric emergency ward of the Niger Delta University Teaching Hospital, Bayelsa State, Nigeria. Niger J Paediatr 2013;40;232-7.

22. Fagbule D, Parakoyi DB, Spiegel R. Acute respiratory infections in Nigerian children: Prospective cohort study of incidence and case management. J Trop Pediatr 1994;40:279-84.

23. Ye Y, Zulu E, Mutisya M, et al. Seasonal pattern of pneumonia mortality among under-five children in Nairobi's informal settlements. Am J Trop Med Hyg 2009;81:770-5.

24. Anyanwu OU, Ezeanosike OB, Ezeonu CT. Pattern and outcome of admissions at the children emergency room at the Federal Teaching Hospital Abakaliki. Afr J Med Health Sci 2014;13:6-10.

25. Ezeonwu BU, Chima OU, Oguonu T, et al. Morbidity and mortality pattern of childhood illnesses seen at children emergency unit of Federal Medical Centre, Asaba, Nigeria. Ann Med Health Sci Res 2014;4:S239-44.

26. Ndukwu CI, Onah SK. Pattern and outcome of postneonatal pediatric emergencies in Nnamdi Azikiwe University Teaching Hospital, Nnewi, South East Nigeria. Niger J Clin Pract 2015;18:348-53.

27. Fajolu IB, Egri-Okwaji MT. Childhood mortality in children emergency centre of the Lagos University Teaching Hospital. Niger J Paediatr 2011;38:1315.

28. Roy RN, Nandy S, Shrivastara P, et al. Mortality pattern of hospitalised children in a tertiary care hospital in Kolkota. Indian J Community Med 2008;33:187-9.

29. Ayoola OO, Orimadegun AE, Akinsola AK, Osinusi K. A five-year review of childhood mortality at the University College Hospital, Ibadan. West Afr J Med 2005;24:175-9. 